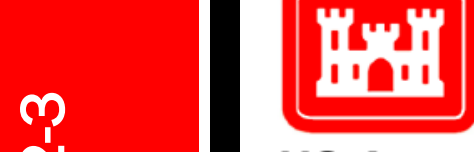

US Army Corps

of Engineers ${ }_{\circledast}$

Engineer Research and

Development Center

\title{
Observation of Crack Arrest in Ice by High Aspect Ratio Particles during Uniaxial Compression
}

Emily Asenath-Smith, Ross Lieblappen, Susan Taylor, Reed R. Winter, Terry D. Melendy Jr., Robert D. Moser, and Robert B. Haehnel

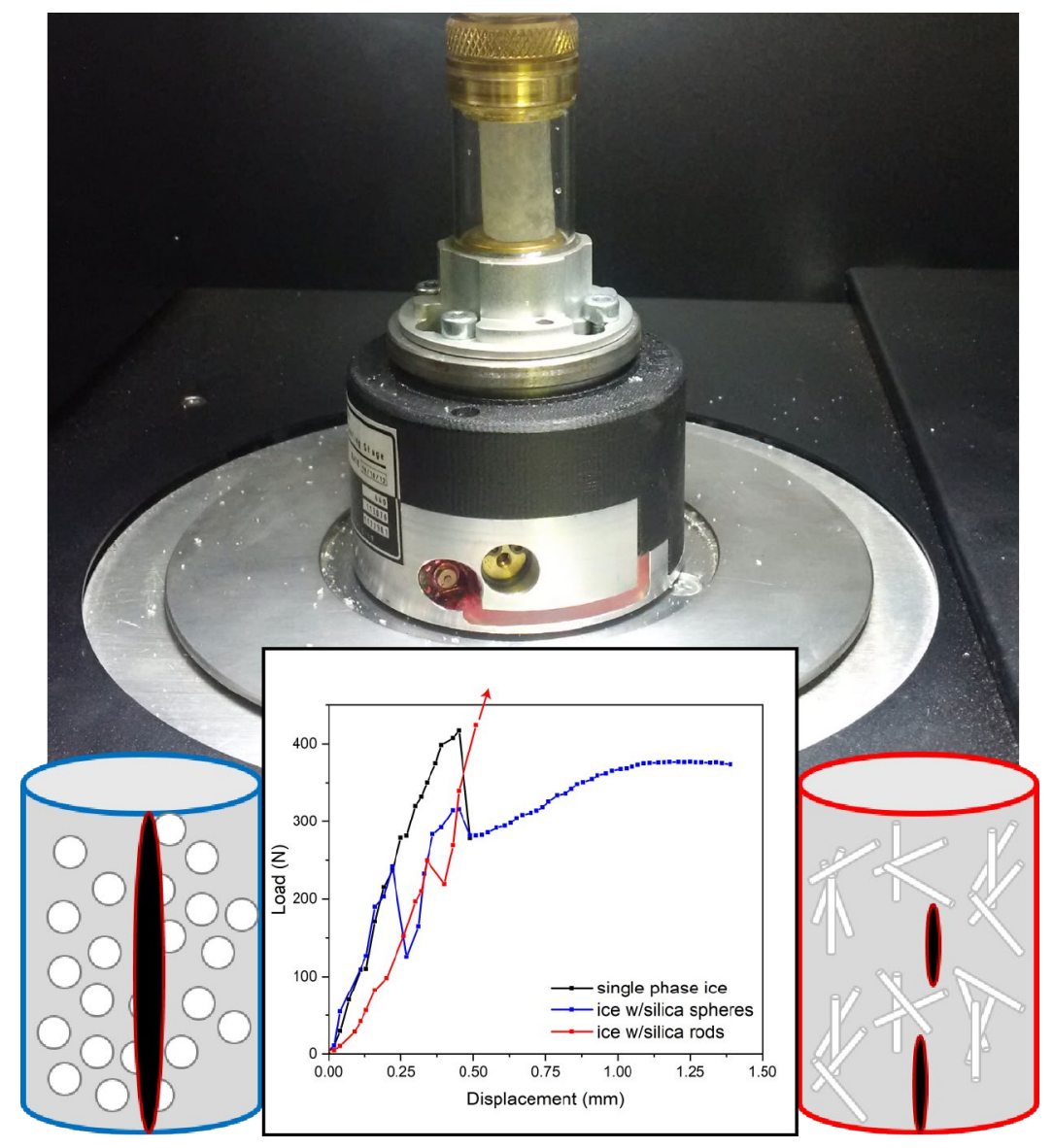


The US Army Engineer Research and Development Center (ERDC) solves the nation's toughest engineering and environmental challenges. ERDC develops innovative solutions in civil and military engineering, geospatial sciences, water resources, and environmental sciences for the Army, the Department of Defense, civilian agencies, and our nation's public good. Find out more at www.erdc.usace.army.mil.

To search for other technical reports published by ERDC, visit the ERDC online library at https://erdclibrary.on.worldcat.org/discovery. 
ERDC TR-22-3

February 2022

\section{Observation of Crack Arrest in Ice by High Aspect Ratio Particles during Uniaxial Compression}

Emily Asenath-Smith, Susan Taylor, Reed R. Winter, Terry D. Melendy Jr., and Robert Haehnel

US Army Engineer Research and Development Center (ERDC)

Cold Regions Research and Engineering Laboratory (CRREL)

72 Lyme Road

Hanover, NH 03755-1290

Robert D. Moser

US Army Engineer Research and Development Center (ERDC)

Geotechnical and Structures Laboratory (GSL)

3909 Halls Ferry Road

Vicksburg, MI 39180

Ross Lieblappen

Vermont Technical College

124 Admin Drive

Randolph, VT 05061

Final Report

Approved for public release; distribution is unlimited.

Prepared for Headquarters, US Army Corps of Engineers

Washington, DC 20314-1000

Under PE 622784/Project 458161/Task 0053 


\section{Abstract}

In nature, ice frequently contains dissolved solutes or entrapped particles, which modify the microstructure and mechanical properties of ice. Seeking to understand the effect of particle shape and geometry on the mechanical properties of ice, we performed experiments on ice containing $15 \mathrm{wt} \%$ silica spheres or rods. Unique to this work was the use of 3-D microstructural imaging in a $-10^{\circ} \mathrm{C}$ cold room during compressive loading of the sample. The silica particles were present in the ice microstructure as randomly dispersed aggregates within grains and at grain boundaries. While cracks originated in particle-free regions in both sphere- and rodcontaining samples, the propagation of cracks was quite different in each type of sample. Cracks propagated uninhibited through aggregates of spherical particles but were observed to arrest at and propagate around aggregates of rods. These results imply that spherical particles do not inhibit grain boundary sliding or increase viscous drag. On the other hand, silica rods were found to span grains, thereby pinning together the microstructure of ice during loading. These results provide insights into mechanisms that can be leveraged to strengthen ice.

DISCLAIMER: The contents of this report are not to be used for advertising, publication, or promotional purposes. Citation of trade names does not constitute an official endorsement or approval of the use of such commercial products. All product names and trademarks cited are the property of their respective owners. The findings of this report are not to be construed as an official Department of the Army position unless so designated by other authorized documents. 


\section{Contents}

Abstract............................................................................................................................... ifi

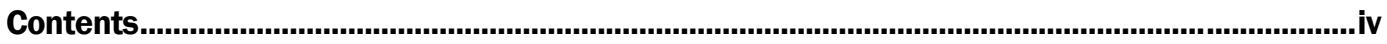

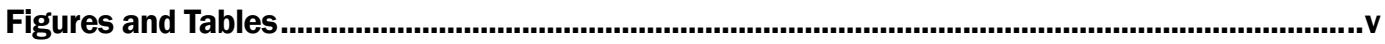

Preface ....................................................................................................................................... vii

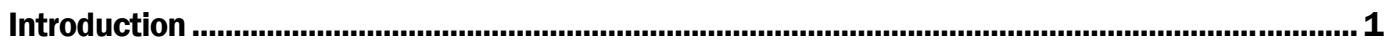

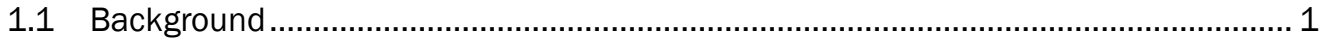

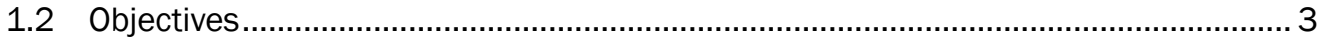

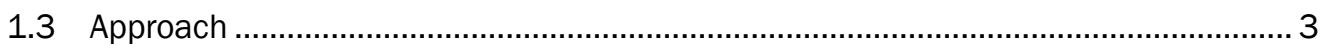

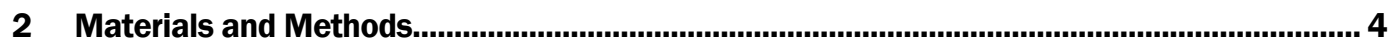

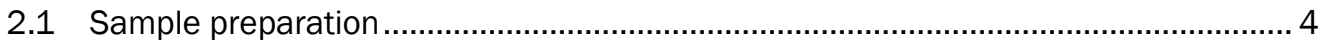

2.2 Microstructural characterization ...................................................................... 4

2.3 X-ray microstructural characterization ............................................................. 5

2.4 In situ mechanical-structural characterization .................................................. 6

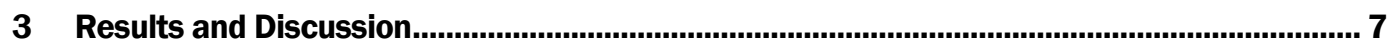

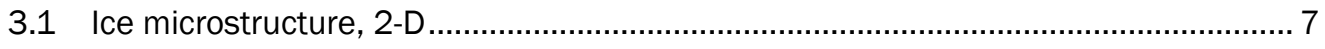

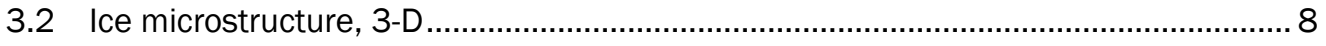

3.3 Microscale in situ mechanical testing ............................................................... 12

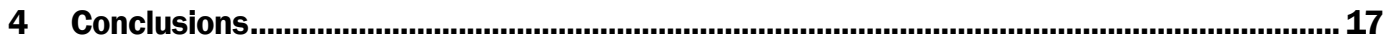

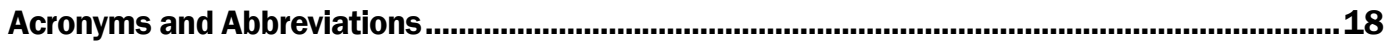

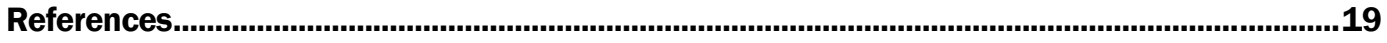

Report Documentation Page ............................................................................................. 23 


\section{Figures and Tables}

\section{Figures}

Figure 1. Measured particle size distributions of the silica particles that were added to the ice specimens: (a) silica spheres and (b) silica rods. Insets:

Representative SEM images of the spheres and rods that were analyzed

using ImageJ to extract the size distributions for each particle type.

Figure 2. Optical micrographs of ice samples at low $(a-c)$ and high $(d-f)$

magnification: $(a, d)$ single-phase polycrystalline ice; $(b, e)$ ice with

entrapped silica spheres; $(c, f)$ ice with entrapped silica rods. Silica

spheres $(e)$ and rods $(f)$ are visible at grain boundaries (arrows) and within

grains (circles).

Figure 3. Three-dimensional tomographic reconstructions of ice with (a) silica spheres and $(b)$ silica rods. Scale values represent the distance between tick marks on the cells surrounding each image. Distribution of silica particles as a function of depth in the ice specimens calculated from micro-CT images: (c) percent volume of silica spheres, (d) percent volume of silica rods.

Figure 4. A graphical illustration of the size relationship between the silica rods and resolution limits in the micro-CT. (a) The relative size between a single silica rod and micro-CT pixel showing the inability of the micro-CT to resolve the diameter of individual rods. Average rod and pixel sizes are listed in the graphic. (b) In the ice specimens, the silica rods form into overlapped, bundled aggregates, which have a central core that can be recorded in multiple micro-CT pixels. (c) The resulting image recorded by the micro-CT contains only a representation of the core region of the silica rod bundles.

Figure 5. In situ structural-mechanical characterization of ice specimens containing silica spheres $(a-c)$ and rods $(d-f)$ performed in the micro-CT: $(a)$ load displacement curve for uniaxial compression of the ice specimen with silica spheres (stars indicate load values where scans were performed); (b) a 2-D slice through the 3-D reconstruction of images acquired after loading the sample to $240 \mathrm{~N}$. Cracks (highlighted with red arrow) originate in particle-free regions (gray background represents ice; black voids are air pockets); (c) and are seen to propagate through aggregates of silica particles (bright white contrast) with continued loading to 375 N. (d) Stress-strain behavior of the ice specimen containing silica rods, noting that the sample did not yield significantly before the maximum force of the load cell ( $400 \mathrm{~N}$ ) was reached. (e) Cracking originates in the pure ice regions (crack highlighted with red arrow); however, upon further loading to $400 \mathrm{~N},(f)$ the crack propagates around the fibrous aggregates (bright white bundles), indicating a strengthening mechanism of crack arrest by the silica rods.

Figure 6. Scanning electron microscopy images of ice samples: (a) polycrystalline ice with silica spheres showing that the spheres are randomly distributed within grains and at grain boundaries and that cracks may originate at spheres, red arrow shows direction of crack extension; (b) polycrystalline ice with silica rods showing that the rods exist as aggregates within grains and at grain boundaries; (c) the ice-rod sample showing the termination of cracks at silica rod aggregates; $(d)$ an ice-rod sample showing that the 
silica rods span grain boundaries, highlighted by red circle. Notes: grain boundaries are apparent in panels $(a)$ and $(b)$ as lines in the ice matrix; cracks seen in panels $(c)$ and $(d)$ were introduced during cleaving of fresh surfaces for SEM imaging.......

\section{Tables}

Table 1. Experimental data on the ice composite samples examined with micro-CT........................ 10

Table 2. Summary of 3-D statistics from micro-CT analysis........................................................... 11 


\section{Preface}

This study was conducted for the U.S. Army Corps of Engineers under PE 622784, Project 458161, Task 0053, "Thermally Resilient Ice Based Composites."

The work was performed by the Force Projection and Sustainment Branch of the Research and Engineering Division, US Army Engineer Research and Development Center (ERDC), Cold Regions Research and Engineering Laboratory (CRREL). At the time of publication, Dr. Wade Lein was Acting Branch Chief, Force Projection and Sustainment Branch; Dr. John W.

Weatherly was Branch Chief, Terrestrial and Cryospheric Science Branch; and Dr. George Calfas was Division Chief. The Acting Deputy Director of ERDC-CRREL was Mr. Bryan E. Baker, and the Director was Dr. Joseph L. Corriveau.

The authors are grateful to Dr. David M. Cole and Dr. Zoe Courville for their advisory roles in this research.

COL Teresa A. Schlosser was Commander of ERDC, and Dr. David W. Pittman was the Director. 


\section{Introduction}

\subsection{Background}

Rarely does ice exist in nature as a pure, single-phase material. More often, it contains dissolved solutes as in sea ice (Gow et al. 1982; Worster and Wettlaufer 1997), entrapped particulates such as in frozen soils (Style et al. 2011), or gas condensates in interstellar ices (Durham, Kirby, and Stern 1992; Yasui and Arakawa 2008). These impurities modulate the ice microstructure and influence the resulting material properties (Hammonds and Baker 2016; Dempsey, Cole, and Wang 2018; Song, Cole, and Baker 2006). Recent years have seen great progress in threedimensional (3-D) characterization of frozen materials, including soils (Bhreasail et al. 2012), sea ice (Lieb-Lappen, Golden, and Obbard 2017), and colloidal suspensions (Deville et al. 2009), yet studies aimed at elucidating the microscale mechanisms by which entrapped particles affect the deformation behavior of ice materials are still sparse. A better understanding of the effects of particles on ice material properties will help predict the strength of ice and frozen soils in cold regions.

As a material with a melting point near ambient global temperatures, ice is relatively weak and susceptible to creep (Schulson 1999; Petrovic 2003; Arakawa and Maeno 1997; Gold 1966). In addition, ice is a viscoelastic material, having a response that depends on the strain rate (Gold 1966). It is stronger in compression than in tension (Sunder and Wu 1990), and the strength of ice depends on grain size (Cole 2001), temperature, and strain rate (Schulson 1990). At low strain rates, ice behaves as a ductile material; at high rates, it has a brittle response; and at intermediate rates, ice can behave as brittle in tension and ductile in compression (Schulson 1999).

The fracture mechanisms in pure ice have been well studied (Gold 1972; Renshaw, Golding, and Schulson 2014; Frost and Smith 1992; Frost 1995). Under compressive loading, cracks nucleate through grain boundary sliding (Picu and Gupta 1995; Weiss, Schulson, and Frost 1996) and elastic anisotropy (Cole 1988). As loading continues, a steady increase in crack density leads to the formation of shear faults, which dictate failure (Schulson 1999). In tension, dislocation increases at grain boundaries nucleate cracks in ice (Currier and Schulson 1982; Sunder and Wu 1990). 
Studies to understand the mechanical properties of ice with a second phase began in the 1940 s and were motivated by materials shortages during WWII (Gold 2004). These efforts, aimed at using ice as an engineering material, demonstrated that ice became significantly stronger by the addition of wood pulp (Abele 1964). When compared to concrete, ice-wood composites have half the weight and cure ten times faster while retaining an equivalent flexural strength ( $\mathrm{Li}$, Wei, and $\mathrm{Wu}$ 2015). When compared to single-phase ice, wood pulp-reinforced ice was found to have up to a threefold greater flexural and compressive strength as well as decreased creep behavior (Vasiliev et al. 2015).

The properties of ice with a second phase are all active topics of study in natural ice (Holdsworth and Bull 1970; Vasiliev et al. 2015), frozen soils (Haynes and Karalius 1977; Schollick et al. 2016), and interstellar bodies (Lange and Ahrens 1983; Durham, Kirby, and Stern 1992). Findings include the effect of particles on the mechanical properties of ice depends on the size of particles in the ice matrix (Song, Baker, and Cole 2005), particles inhibit grain boundary sliding under creep (Song, Cole, and Baker 2006), the peak stress increases with increasing particle content (Yasui and Arakawa 2008; Durham, Kirby, and Stern 1992), the distribution of particles within the ice microstructure depends on the freezing conditions (Schollick et al. 2016; Deville et al. 2010), and entrapped particulates influence dynamic recrystallization processes in ice (Cyprych, Brune, et al. 2016; Cyprych, Piazolo, et al. 2016; Baker and Gerberich 1979).

These studies show that the effect of particles on ice mechanical properties is not yet clearly understood; studies of natural ice have concluded that the weight or volume percent of particles determines ice strength, while testing of ice shows that the modulus and aspect ratio of the second phase material determine the ice strength (Vasiliev 1993; Kingery 1963). We think these inconsistent conclusions stem from not knowing how secondphase materials affect crack propagation in ice during compressive loading. Studies that can image the microscale structural evolution of materials during loading (Cil, Alshibli, and Kenesei 2017) are key to understanding this process.

For single-phase ice and two-phase snow (ice-air), correlating structureproperties using $\mathrm{X}$-ray imaging is difficult due to the low scattering cross 
section of $\mathrm{H}_{2} \mathrm{O}$ and ice's low melting temperature. Nevertheless, in situ loading and X-ray imaging of low density snow (Wang and Baker 2013; Schleef, Löwe, and Schneebeli 2014) and images of pure (Liu et al. 1992) and ex situ damaged (Hammonds and Baker 2017) polycrystalline ice have all been accomplished. For ice with a silica second phase, X-ray imaging is easier as silica atoms have a higher electron density than water molecules.

\subsection{Objectives}

Here, we report on the structure and mechanical properties of two icesilica mixtures-the first using spherical silica particles and the second using silica rods.

\subsection{Approach}

We observed microscale crack propagation by using x-ray microcomputed tomography (micro-CT) to image the sample during in situ uniaxial compression. These tests were performed in a cold room at $-10^{\circ} \mathrm{C}$. By testing both spheres and rods under the same conditions, we have identified the critical role played by the aspect ratio of the silica phase on the macroscale strength of ice. 


\section{Materials and Methods}

For these tests we grew ice containing $\sim 15$ wt\% of either industrial glass beads (Mil-G-9954A, Flex-O-Lite, St. Louis, MO) or milled glass fibers. The size distributions for the spheres and rods were measured from micrographs (imaging instrument and conditions described below) with Image $J$, a freeware image processing program. The spherical silica glass beads had diameter $(\mathrm{d})=276 \pm 47 \mu \mathrm{m}$ (Figure $1 a$ ), and the rod-like particles were measured to have length $(\mathrm{l})=340 \pm 200 \mu \mathrm{m}$, width $(\mathrm{w})=22$ $\pm 3 \mu \mathrm{m}$, aspect ratio $\sim 15$ (Figure 1b) (Fibertec, Bridgewater, MA). Water for the ice was deionized Milli-Q ( $>10 \mathrm{M} \Omega \mathrm{cm}^{-1}$, Millipore, Burlington, MA) and deaerated with a Nold DeAerator (Model 2100, GEOKON, Lebanon, $\mathrm{NH})$ before freezing.

\subsection{Sample preparation}

To grow single-phase polycrystalline ice, we froze deionized, deaerated (dida) water in covered containers. This ice was then ground and sieved through a $2 \mathrm{~mm}$ (No. 10) mesh to exclude grains $>2 \mathrm{~mm}$. The $<2 \mathrm{~mm}$ ice grains were placed in specially designed cylindrical molds (diameter $=2$ inches) (Schwarz et al. 1981) and flooded with di-da water.

To make ice containing $15 \mathrm{wt} \%$ silica particles, the correct mass of particles was first mixed with $\sim 2 / 3$ of the corresponding amount of di-da water by freezing in layers (e.g., particles, water, particles, water). After freezing, the ice-particle mass was ground and sieved to $<2 \mathrm{~mm}$, as described in Song, Cole, and Baker (2005); Durham, Kirby, and Stern (1992); and Yasui and Arakawa (2008). The ice-silica grains were then mixed as a slurry with the remaining $1 / 3$ water needed and packed into cylindrical molds. All specimens were placed in a temperature-controlled environment at $-5^{\circ} \mathrm{C}$, where freezing took place over the course of 24 hours. This preparation process allowed us to achieve the target silica particle content in the completed specimens.

\subsection{Microstructural characterization}

All microstructural characterization was conducted in a cold room at $-16^{\circ} \mathrm{C}$. Thin sections were taken perpendicular to the long axis of cylindrical ice specimens and thinned to $\sim 1 \mathrm{~mm}$ with a sliding microtome 
(SM2400, Leica Biosystems, Feasterville, PA). Specimens were imaged under cross-polarized light with a stereo microscope (SZH10, Olympus, USA) equipped with a centered rotating stage; images were acquired with a 6.o megapixel CCD camera (Infinity3-6UR, Lumenera, Ottawa, ON). The mean grain size of the ice samples was determined by image analysis with ImageJ.

Scanning electron microscopy (SEM), operating at 15 kilovolts $(\mathrm{kV})$, was used to image and characterize the native spheres and rod-like particles used in these tests (Phenom Pro X, Thermo Fisher Scientific, Hudson, $\mathrm{NH}$ ). A field emission SEM (Scios 2 LoVac, FEI, Thermo Fisher Scientific), equipped with a cold stage (Gatan, Pleasanton, CA) and operating at $5 \mathrm{kV}$, was used to image the ice samples containing spheres or rods after compression testing.

\subsection{X-ray microstructural characterization}

Three-dimensional (3-D) microstructural characterization was performed at $-10^{\circ} \mathrm{C}$ with a micro-CT scanner (SkyScan 1173 , Bruker, Billerica, MA) equipped with a Hamamatsu 130/300 tungsten X-ray source and a flatpanel sensor camera detector with $2240 \times 2240$ pixels. We set the maximum accelerating voltage of the X-ray beam at $60 \mathrm{kV}$ with $110 \mu \mathrm{A}$. Samples were rotated $180^{\circ}$ in $0.4^{\circ}$ steps, with a 4-frame averaged attenuation image captured at each step using a camera exposure of 250 $\mathrm{msec}$. We used a $2 \times 2$ binning protocol to create $\mathrm{X}$-ray radiographs at $1120 \times 1120$ pixels. The resulting radiographs were reconstructed using Bruker Skyscan's NRECON ${ }^{\circledR}$ software, which uses a modified Feldkamp cone-beam algorithm to produce a vertical stack of grayscale crosssectional images. As part of image post-processing, we performed ring artifact reduction, post-alignment correction, beam hardening correction, and a two-pixel Gaussian kernel smoothing to reduce noise. The resulting images had a nominal spatial resolution of $19.9 \mu \mathrm{m}$.

Microstructural analysis was done on an interior cylindrical volume of interest measuring $14.7 \mathrm{~mm}^{3}$ (11.5 $\mathrm{mm}$ diameter and $14.2 \mathrm{~mm}$ length) for silica spheres and $20.5 \mathrm{~mm}^{3}$ (12.0 mm diameter and $18.2 \mathrm{~mm}$ length) for silica fibers. We used a histogram shape-based approach to set critical thresholds to segment the silica, air, and ice phases. For each binarized 
phase, we performed both 2-D and 3-D microstructural analysis using Bruker Skyscan's CTAn ${ }^{\circledR}$ software.

\subsection{In situ mechanical-structural characterization}

Small cylindrical specimens (approximate diameter $=12 \mathrm{~mm}$, length $=21$ $\mathrm{mm}$ ) were milled from the 2 inch diameter cylindrical specimens for in situ mechanical testing and 3-D imaging. Uniaxial compression was performed using a SkyScan Material Testing Stage (Bruker). Although we were unable to estimate loading rate because time information was not available in the system, we compressed continuously, with 20-minute pauses at 100, 250, and 400 Newtons (N) to allow for imaging. Although these pauses may have caused ice relaxation and affected the ice's ultimate strength, the pauses should not have affected the relative differences in ultimate strength between samples. 


\section{Results and Discussion}

Aiming to understand the role that particle shape plays in strengthening ice, we investigated the microstructure, compressive strength, and microstructure evolution during compressive loading of ice with entrapped silica spheres $(\mathrm{d}=276 \pm 47 \mu \mathrm{m}$, Figure $1 a)$ and rods $(\mathrm{l}=340 \pm 200 \mu \mathrm{m}, \mathrm{w}$ $=22 \pm 3 \mu \mathrm{m}$, aspect ratio $\sim 15$, Figure $1 b$ ).

Figure 1. Measured particle size distributions of the silica particles that were added to the ice specimens: (a) silica spheres and (b) silica rods. Insets: Representative SEM images of the spheres and rods that were analyzed using ImageJ to extract the size distributions for each particle type.

a)

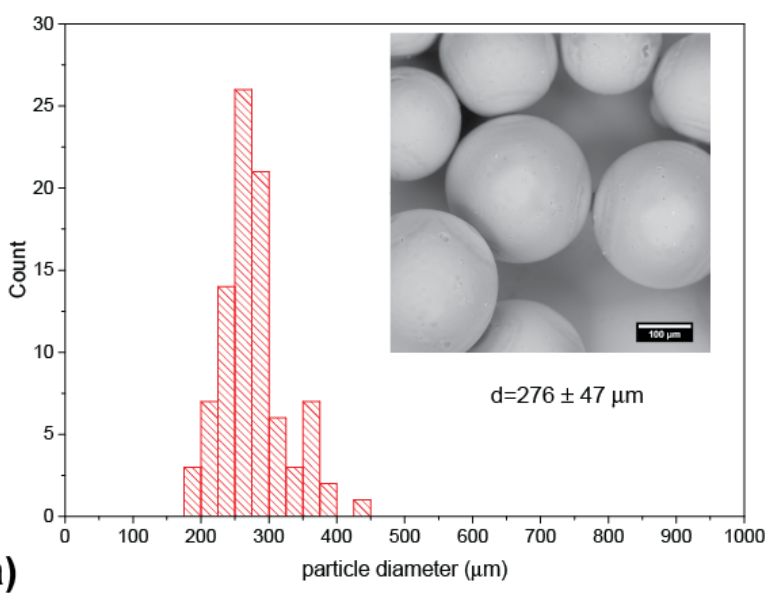

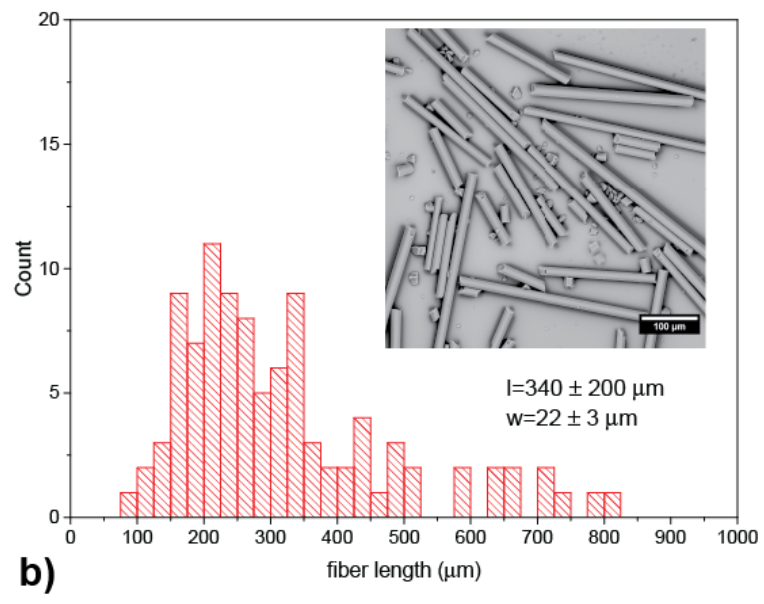

\subsection{Ice microstructure, 2-D}

Optical examination of the ice samples shows that single phase polycrystalline ice specimens had a mean grain size of $2.4 \pm 1.8 \mathrm{~mm}$, a density of $0.88 \pm 0.02 \mathrm{~g} / \mathrm{cm}^{3}$, and consistent microstructures (Figure $2 a, d)$. The ice samples containing silica spheres had an average grain size of $1.1 \pm 0.4 \mathrm{~mm}$ and a density of $0.985 \mathrm{~g} / \mathrm{cm}^{3}$, while ice samples that contained silica rods had an average grain size of $0.6 \pm 0.3 \mathrm{~mm}$ and a density of $0.949 \mathrm{~g} / \mathrm{cm}^{3}$. These results indicate that our ice synthesis process is sufficient at producing high density ices with little entrapped air. The increase in density of the ice specimens containing $15 \mathrm{wt} \%$ particles is likely caused by the larger density of the entrapped silica phase. 
Figure 2. Optical micrographs of ice samples at low $(a-c)$ and high $(d-f)$ magnification: $(a, d)$ single-phase polycrystalline ice; $(b, e)$ ice with entrapped silica spheres; $(c, f)$ ice with entrapped silica rods. Silica spheres $(e)$ and rods ( $f$ are visible at grain boundaries (arrows) and within grains (circles).
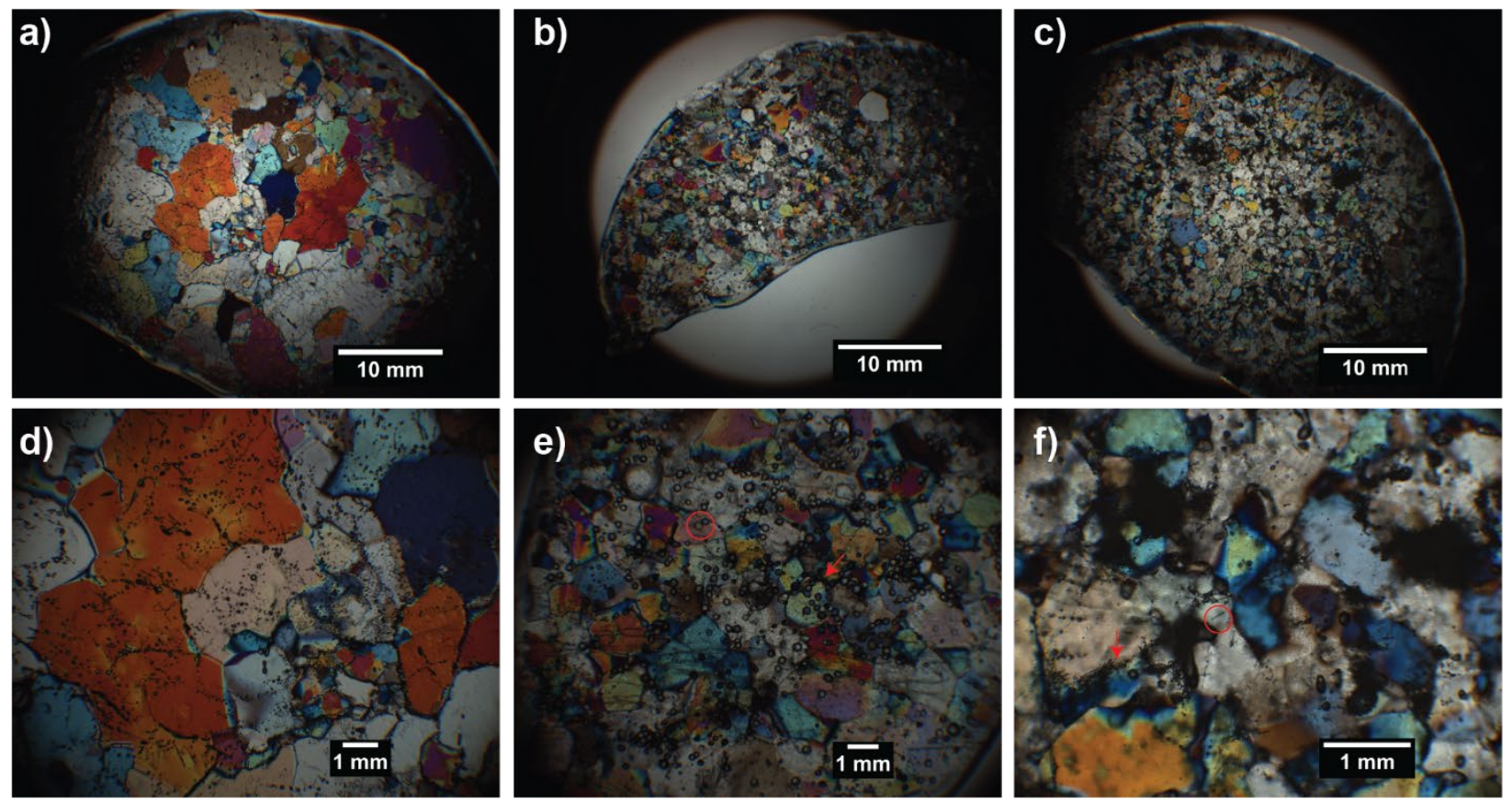

\subsection{Ice microstructure, 3-D}

The micro-CT 3 -D reconstructions (Figure $3 a, b$ ) were used to study the distribution of silica particles within the ice specimens. The images show that we were able to easily resolve the shapes and distribution of the silica spheres. The radial dimensions of the silica rods, however, presented a resolution challenge. While the median length of the silica rods $(340 \pm$ $200 \mu \mathrm{m}$ ) is well within the resolution limit of the micro-CT (pixel $=20$ $\mu \mathrm{m})$, their diameters $(22 \pm 3 \mu \mathrm{m})$ are at the resolution limit (Figure 4). As a result, individual rods are not resolved in the 3 -D reconstructions. The intersecting regions within the silica rod aggregates are dense enough to enable their visibility, and they are distributed throughout the bulk of the ice specimens (Figure $3 b$ ). 
Figure 3. Three-dimensional tomographic reconstructions of ice with (a) silica spheres and (b) silica rods. Scale values represent the distance between tick marks on the cells surrounding each image. Distribution of silica particles as a function of depth in the ice specimens calculated rom micro-CT images: (c) percent volume of silica spheres, (d) percent volume of silica rods.
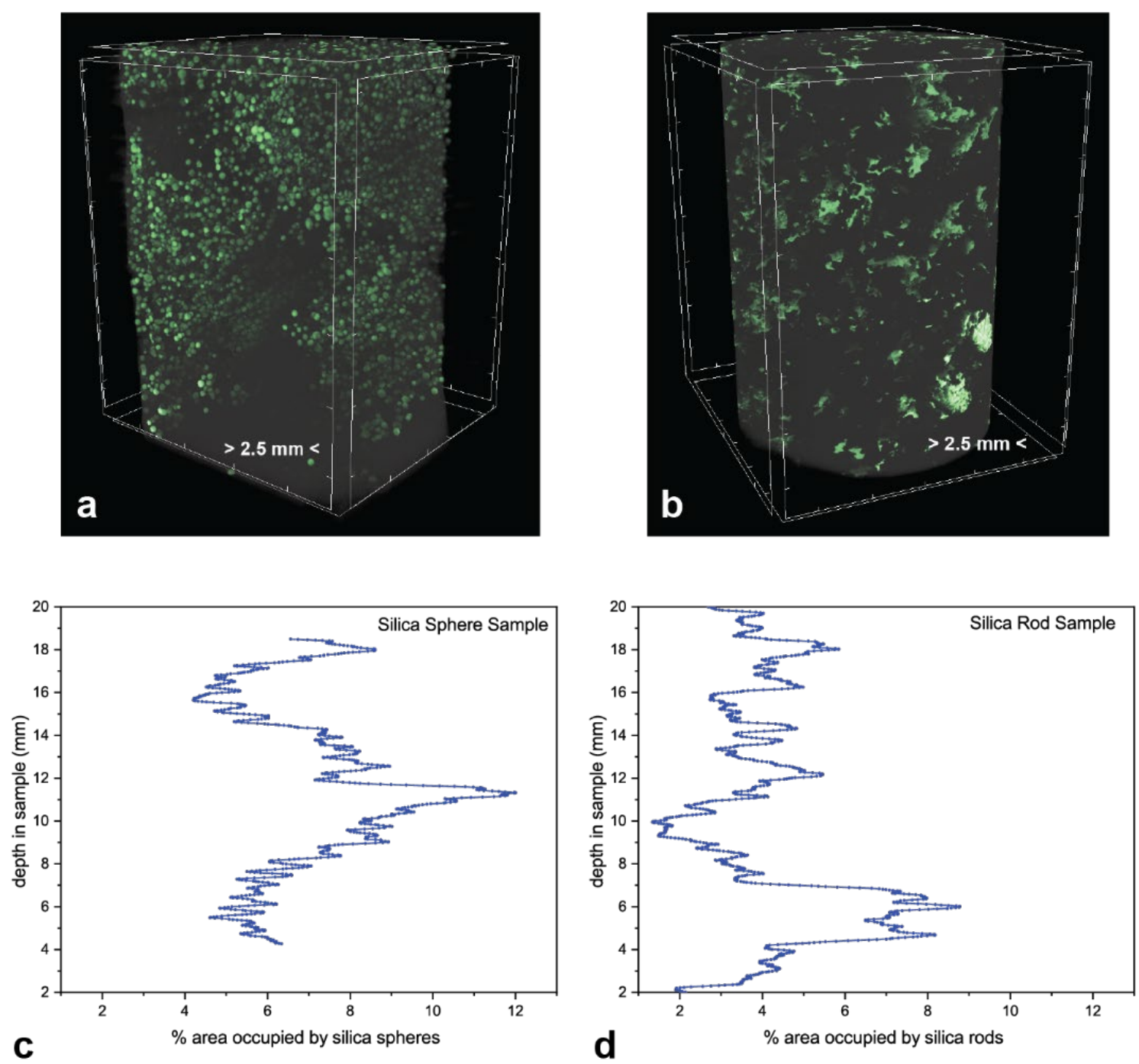
Figure 4. A graphical illustration of the size relationship between the silica rods and resolution limits in the micro-CT. (a) The relative size between a single silica rod and micro-CT pixel showing the inability of the micro-CT to resolve the diameter of individual rods. Average rod and pixel sizes are listed in the graphic. (b) In the ice specimens, the silica rods form into overlapped, bundled aggregates, which have a central core that can be recorded in multiple micro-CT pixels. (c) The resulting image recorded by the micro-CT contains only a representation of the core region of the silica rod bundles.

a)

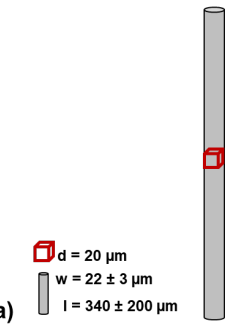

b)

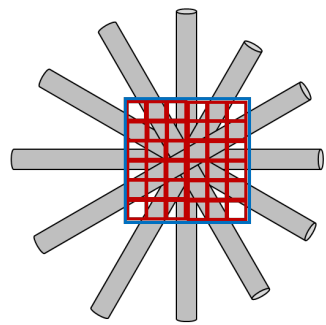

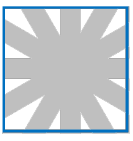

c)

A goal in using micro-CT was to characterize silica particle and air pore distributions before they were subject to compressive loading. We did this by selecting cylindrical regions of interest (14.7 and $20.5 \mathrm{~mm}^{3}$ for spheres and rods, respectively) and determining the volume fraction of silica particles in each specimen to be 0.053 for the silica spheres and 0.040 for the rods (Table 1). Then the volume fraction was converted to a weight percent using the density of silica $\left(2.65 \mathrm{~g} / \mathrm{cm}^{3}\right)$. This analysis indicates 14.0 wt\% silica in the ice specimens containing silica spheres and $10.6 \mathrm{wt} \%$ silica in the specimens containing rods. These values are consistent with the batch amount of $15 \mathrm{wt} \%$, with the lower amount calculated for the rod specimens due to an inability to resolve the individual rods.

Table 1. Experimental data on the ice composite samples examined with micro-CT.

\begin{tabular}{|c|c|c|c|c|}
\hline $\begin{array}{l}\text { Silica particle } \\
\text { shape }\end{array}$ & $\begin{array}{l}\text { Volume fraction } \\
\text { silica particles }\end{array}$ & $\begin{array}{l}\text { Weight percent silica } \\
\text { particles }^{b}\end{array}$ & $\begin{array}{l}\text { Sample } \\
\text { density } \\
\left(\mathrm{g} / \mathrm{cm}^{3}\right)^{c}\end{array}$ & $\begin{array}{l}\text { Sample } \\
\text { porosity (\%) }\end{array}$ \\
\hline Spheres & 0.053 & 14.0 & 0.985 & 1.69 \\
\hline Rods & 0.040 & 10.6 & 0.949 & 0.13 \\
\hline
\end{tabular}

aCalculated from micro-CT scans using CTAN software

bCalculated from volume fraction and $\rho_{\mathrm{SiO}_{2}}=2.65 \mathrm{~g} / \mathrm{cm}^{3}$

'Density values were calculated from $\rho_{I C}=\sum_{i} \chi_{i} \rho_{i}$, using $\rho_{i c e}=0.88 \mathrm{~g} / \mathrm{cm}^{3}$ and

$\rho_{\text {SiO }_{2}}=2.65 \mathrm{~g} / \mathrm{cm}^{3}$

dPorosity values were determined from the calculated \% volume air

The 3-D statistics from micro-CT analysis on the region of interest were used to study the air voids in the ice specimens. For the silica sphere samples, $1.3 \mathrm{vol} \%$ of the volume was calculated to be air and voids, and the 
ice containing silica rods was found to have a 0.13 vol\% air/void volume (Table 2). These porosity values are quite small and consistent with the measured densities of $0.985 \mathrm{~g} / \mathrm{cm}^{3}$ and $0.949 \mathrm{~g} / \mathrm{cm}^{3}$ for the sphere and rod specimens respectively (Table 1), confirming that the synthesis procedure results in solid, dense specimens.

The micro-CT data also allowed us to analyze the area occupied by the silica materials as a function of depth for a vertical slice of interest taken through the 3-D reconstruction (Figure $4 c, d$, Table 2). We found that the percent abundance of silica materials ranged from 6-12 area\% and from 2-8 area\% along the length of the ice specimens with silica spheres and rods, respectively. This variation is also apparent in the $3-\mathrm{D}$ reconstructions themselves and is consistent with a heterogenous distribution of silica particles within the specimens.

Other statistics derived from the micro-CT imaging further describe the pore and silica inclusion characteristics. For example, the air phase in the ice samples that contained silica rods had the highest surface-to-volume ratio (78\%), indicating smaller air pore/voids. The 0.07 degree of anisotropy found for the sphere phase is consistent with their spherical, low aspect ratio shape. The degree of anisotropy of 0.25 and 0.32 for the rods and air in the rod specimens implies that the rods and pores have irregular shapes in these specimens. Given the resolution limits on the rod diameters, these findings are consistent with the irregularly shaped masses seen in the reconstructions (Figure $3 a, b$ ).

Table 2. Summary of 3-D statistics from micro-CT analysis.

\begin{tabular}{|l|l|l|l|l|}
\hline \multirow{2}{*}{} & \multicolumn{2}{|c|}{ Silica Spheres } & \multicolumn{2}{c|}{ Silica Rods } \\
\cline { 2 - 6 } & Air & Spheres & Air & Rods \\
\hline Percent object volume & 1.3 & 5.3 & 0.13 & 4.0 \\
\hline Object surface-to-volume ratio & 24.9 & 24.5 & 78.0 & 26.0 \\
\hline Degree of anisotropy & 0.29 & 0.07 & 0.32 & 0.25 \\
\hline
\end{tabular}




\subsection{Microscale in situ mechanical testing}

To study the effect of silica particles on the mechanical properties of ice, we performed uniaxial compression experiments on small cylindrical specimens $(\mathrm{d}=12 \mathrm{~mm}, \mathrm{l}=21 \mathrm{~mm})$ using a load frame within the micro-CT. With this setup, we were able to pause the loading at various levels to perform microstructural imaging ( 20 minute scans), allowing us to visualize the ice response "in real time." A maximum load of $400 \mathrm{~N}$ was possible, and we imaged the samples after $0, \sim 100, \sim 250$, and $\sim 400 \mathrm{~N}$ loading.

The ice sample containing silica spheres exhibited an onset of cracking at $\sim 0.03 \%$ strain (Figure $5 a$ ), which was associated with the formation of cracks in particle-free regions of the ice microstructure (Figure $5 b$ ). With continued loading, cracks propagated through the aggregates of silica spheres (Figure $5 c$ ), and only $375 \mathrm{~N}$ was sustained by the sample. The samples containing silica rods showed very different behavior. First, the onset of cracking wasn't seen until $>0.06 \%$ strain (Figure $5 d$ ), and the 400 $\mathrm{N}$ load cell was not sufficient to reach the sample's sustainable peak stress; thus the stress-strain curve doesn't level off as it did for the sphere sample. Similar to the sphere sample, the onset of cracking is observed in the particle-free regions (Figure $5 e$ ). However, in contrast to the sphere samples, crack propagation is arrested at fiber aggregates (Figure $5 f$ ); the long vertical crack seen in panel $(e)$ does not propagate through the silica rod aggregate highlighted with a red circle in panel $(f)$. 
Figure 5. In situ structural-mechanical characterization of ice specimens containing silica spheres $(a-c)$ and rods $(d-f)$ performed in the micro-CT: (a) load displacement curve for uniaxial compression of the ice specimen with silica spheres (stars indicate load values where scans were performed); (b) a 2-D slice through the 3-D reconstruction of images acquired after loading the sample to $240 \mathrm{~N}$. Cracks (highlighted with red arrow) originate in particlefree regions (gray background represents ice; black voids are air pockets); (c) and are seen to propagate through aggregates of silica particles (bright white contrast) with continued loading to $375 \mathrm{~N}$. (d) Stress-strain behavior of the ice specimen containing silica rods, noting that the sample did not yield significantly before the maximum force of the load cell ( $400 \mathrm{~N}$ ) was reached. (e) Cracking originates in the pure ice regions (crack highlighted with red arrow);

however, upon further loading to $400 \mathrm{~N},(f)$ the crack propagates around the fibrous aggregates (bright white bundles), indicating a strengthening mechanism of crack arrest by the silica rods.
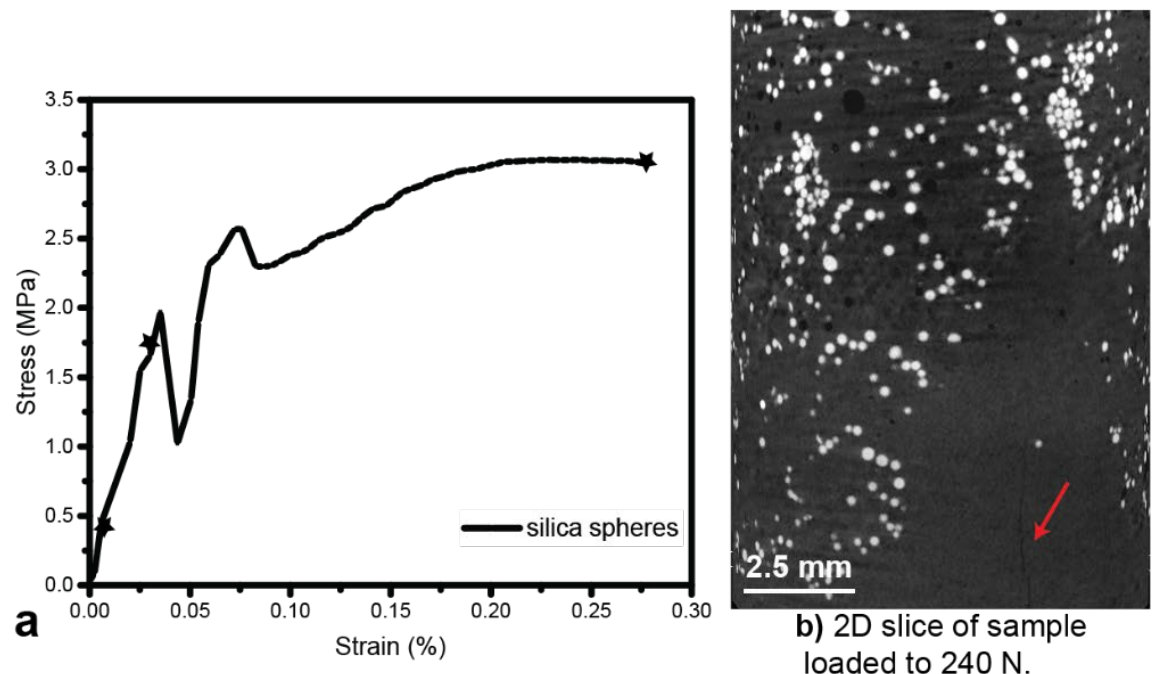

b) $2 \mathrm{D}$ slice of sample loaded to $240 \mathrm{~N}$.

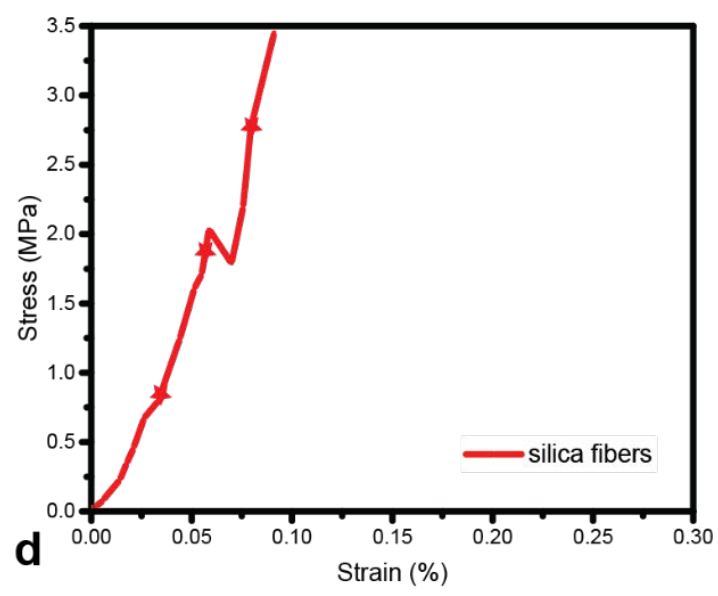

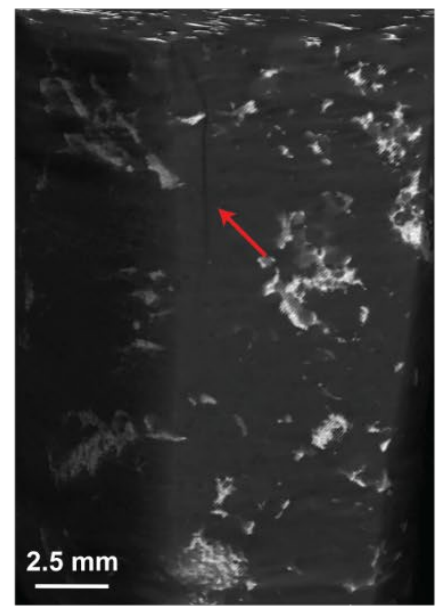

e) 2D slice of sample loaded to $250 \mathrm{~N}$.

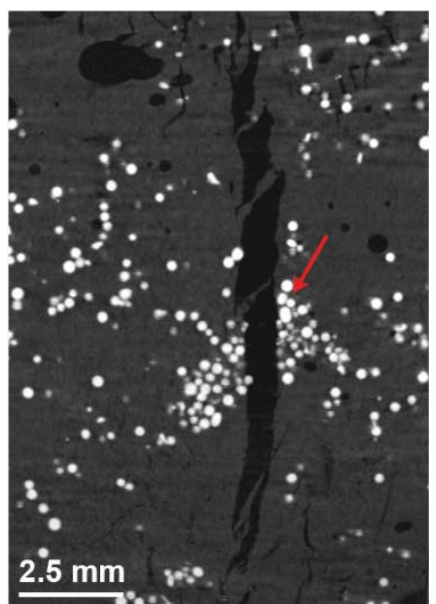

c) 2D slice of sample loaded to $375 \mathrm{~N}$

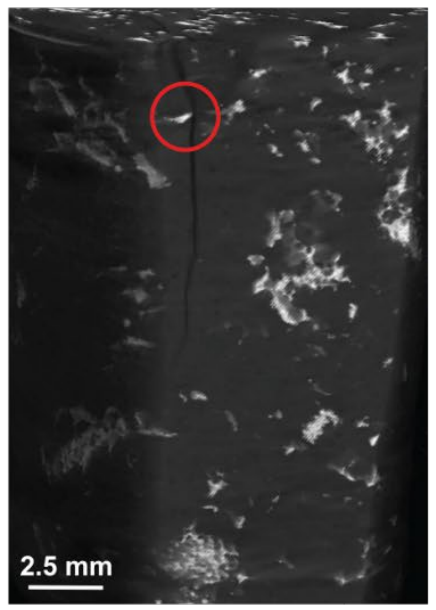

f) 2D slice of sample loaded to $400 \mathrm{~N}$.

Crack nucleation mechanisms depend on ice structure and loading rate (Cole 1988). It is generally accepted that cracks in ice can nucleate by a dislocation pileup mechanism, which is strain and time dependent, and by 
an elastic mechanism, a consequence of lattice anisotropy that forms cracks at grain boundaries (Cole 1986; Gold 1972). Our pseudo-in-situ loading results are consistent with these prior studies. Our observations that cracks originate in particle-free regions suggest that cracks nucleate by dislocation pileup at grain boundaries. The micro-CT did not allow us to determine if cracks occurred preferentially within grains or at grain boundaries; however, we did observe long-range propagation of cracks that parallel the loading axis during loading (Lawrence and Cole 1982).

To expand upon the micro-CT data, we cleaved ice specimens after the compression tests and examined their surfaces by SEM. As observed in optical microscopy and micro-CT, both the silica spheres and rods are found within grains and at grain boundaries and there are minimal air voids and pores (Figure $6 a, b$ ). The images of the silica sphere specimens show evidence that cracks may originate at the spheres (Figure $6 a$, red circle), but in the specimens that contained silica rods, the cracks appear to terminate at the rod aggregates (Figure $6 c$ ). In addition, there were occurrences where both single and aggregates of silica rods spanned cracks and boundaries (Figure $6 d$ ). 
Figure 6. Scanning electron microscopy images of ice samples: (a) polycrystalline ice with silica spheres showing that the spheres are randomly distributed within grains and at grain boundaries and that cracks may originate at spheres, red arrow shows direction of crack extension; (b) polycrystalline ice with silica rods showing that the rods exist as aggregates within grains and at grain boundaries; $(c)$ the ice-rod sample showing the termination of cracks at silica rod aggregates; ( $d$ ) an ice-rod sample showing that the silica rods span grain boundaries, highlighted by red circle. Notes: grain boundaries are apparent in panels $(a)$ and $(b)$ as lines in the ice matrix; cracks seen in panels $(c)$ and $(d)$ were introduced during cleaving of fresh surfaces for SEM imaging.
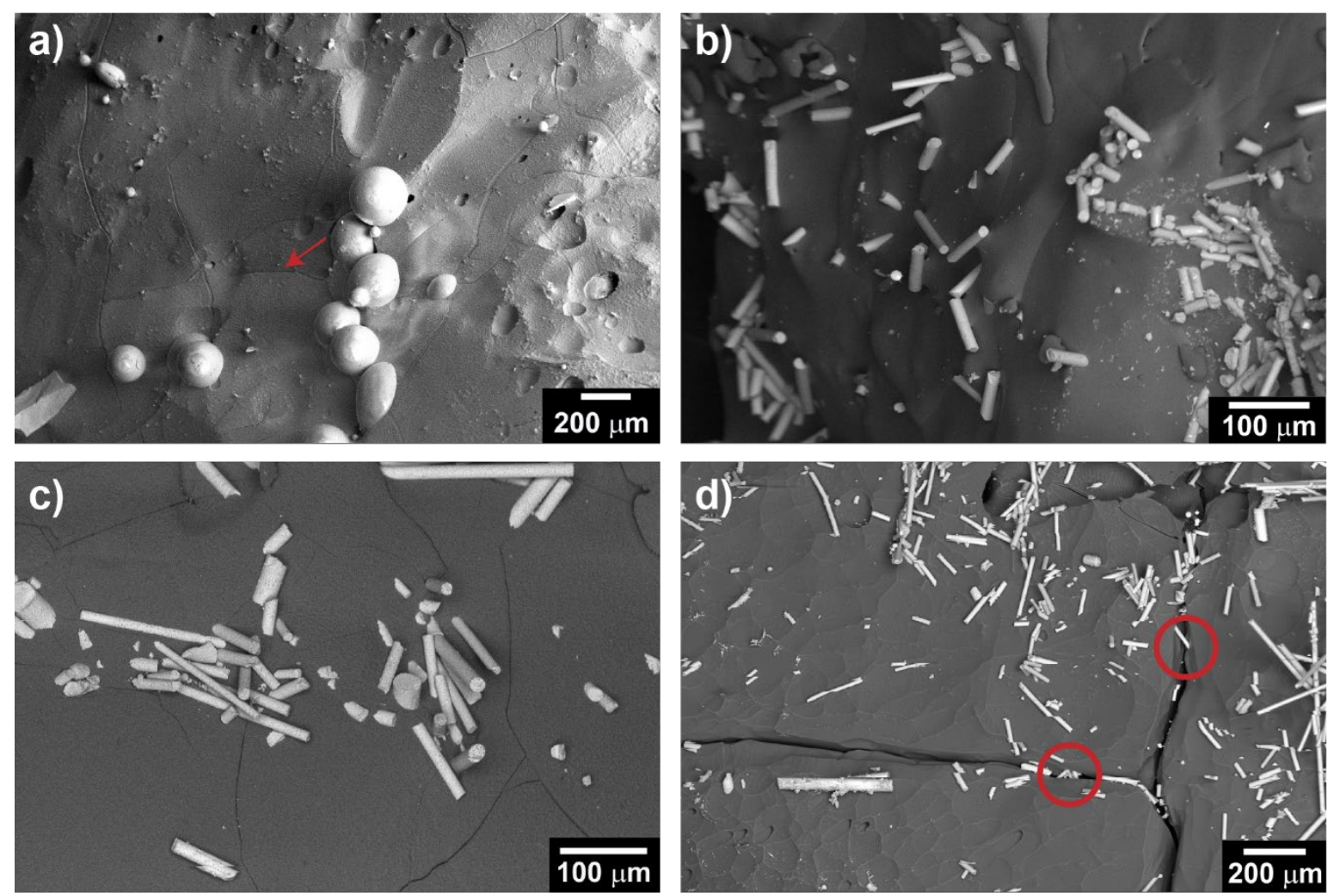

Our compression results show that ice samples containing silica rods are stronger (Figure $5 d$ ), which may be a consequence of the existence of rods that bridge grains and cracks (Figure $6 d$ ) within the ice microstructure. Moreover, cracks terminate at aggregates of rods (Figure $6 d$ ), and during loading, they propagate around aggregates of rods (Figure $5 f$ ). In contrast, in the silica sphere specimens the spheres may serve as an initiator for the formation of secondary cracks. These results are consistent with silica rods strengthening ice by both inhibition of grain boundary sliding and introduction of viscous drag. In addition, the silica rod particles may dissipate energy through deformation of the rod in the elastic range and through rod pullout (Ranade et al. 2013). 
The result that spherical particles do not inhibit crack propagation (Figure $5 c$ ) and may facilitate crack formation (Figure $6 a$ ) implies that silica spheres are not effective at strengthening ice. While many previous reports on particles in ice have simply associated size and relative abundance with strengthening (Durham, Kirby, and Stern 1992; Yasui and Arakawa 2008; Song, Cole, and Baker 2005), some reports have addressed shape, orientation, and hardness of the particles within ice (Vasiliev 1993; Kingery 1963; Cyprych, Brune, et al. 2016; Cyprych, Piazolo, et al. 2016). In short, randomly dispersed glass fibers (length $=25 \mathrm{~mm}$ ) in ice are associated with a two-fold increase in strength of ice under compressive or flexural loading, and greater strength gains are achieved when the fiber orientation is controlled (Vasiliev 1993). While these glass fibers were approximately 100 times greater in length than the silica rods reported herein, our microscale results provide confirmation of older reports that predate the advanced characterization tools such as micro-CT and bring new insight into how second-phase particles interact with ice microstructures during compressive loading. 


\section{Conclusions}

In this report, we have used state-of-the-art microscale materials characterization and property measurements, including in situ methods, to identify the strengthening mechanism(s) that high aspect ratio silica rods impart to ice. Both silica spheres and rods were randomly dispersed throughout grains and grain boundaries in the ice microstructure, yet the mechanical response of the ice depended on the shape of the second-phase particle. While cracks were arrested by aggregates of silica rods within the ice microstructure during compressive loading, they propagated completely through aggregates of spheres and may have originated at sphere surfaces. The silica rods arrest cracks in a manner consistent with grain boundary bridging and viscous drag mechanisms proposed previously. Microscale studies such as those reported here will provide the scientific basis for understanding the behavior of frozen soils and ice covers in cold regions. 


\section{Acronyms and Abbreviations}

$\begin{array}{ll}\text { CCD } & \text { charge-coupled device } \\ \text { CRREL } & \text { Cold Regions Research and Engineering Laboratory } \\ \text { CTAN } & \text { Comprehensive TeX Archive Network } \\ \text { ERDC } & \text { Engineer Research and Development Center } \\ \text { ESM } & \text { engine start module } \\ \text { Micro-CT } & \text { microcomputed tomography } \\ \text { MIL } & \text { Military Specification } \\ \text { MILES } & \text { Multiple Integrated Laster Engagement System } \\ \text { RDTE } & \text { Research, Development, Test, and Evaluation } \\ \text { RPM } & \text { revolutions per minute } \\ \text { SEM } & \text { scanning electron microscopy } \\ \text { VCU } & \text { vehicle control unit }\end{array}$




\section{References}

Abele, G. 1964. Some Properties of Sawdust-Snow-Ice Mixtures. Hanover, NH: Engineer Research and Development Center-Cold Regions Research and Engineering Laboratory (ERDC-CRREL).

Arakawa, Masahiko, and Norikazu Maeno. 1997. "Mechanical Strength of Polycrystalline Ice under Uniaxial Compression." Cold Regions Science and Technology 26 (3): 215-29.

Baker, Robert W., and William W Gerberich. 1979. "The Effect of Crystal Size and Dispersed-Solid Inclusions on the Activation Energy for Creep of Ice." Journal of Glaciology 24 (90): 179-94.

Bhreasail, Á. N., P. D. Lee, C. O'Sullivan, C. H. Fenton, R. Hamilton, P. Rockett, and T. Connolley. 2012. "In-Situ Observation of Cracks in Frozen Soil using Synchrotron Tomography." Permafrost and Periglacial Processes 23 (2): 170-76.

Cil, Mehmet B., Khalid A. Alshibli, and Peter Kenesei. 2017. "3D Experimental Measurement of Lattice Strain and Fracture Behavior of Sand Particles Using Synchrotron X-Ray Diffraction and Tomography." Journal of Geotechnical and Geoenvironmental Engineering 143 (9): 04017048.

Cole, D. M. 2001. "The Microstructure of Ice and Its Influence on Mechanical Properties." Engineering Fracture Mechanics 68 (17-18): 1797-22. doi: 10.1016/soo137944(01)00031-5.

Cole, D. M. 1988. "Crack Nucleation in Polycrystalline Ice." Cold Regions Science and Technology 15 (1): 79-87. https://dx.doi.org/10.1016/0165-232X(88)90041-9.

Cole, D. M. 1986. "Effect of Grain Size on the Internal Fracturing of Polycrystalline Ice." CRREL Report 86 (5): 1-71.

Currier, J. H., and E. M. Schulson. 1982. "The Tensile Strength of Ice as a Function of Grain Size." Acta Metallurgica 30 (8): 1511-14.

Cyprych, D., S. Brune, S. Piazolo, and J. Quinteros. 2016. "Strain Localization in Polycrystalline Material with Second Phase Particles: Numerical Modeling with Application to Ice Mixtures." Geochemistry Geophysics Geosystems 17 (9): 3608-28. doi: 10.1002/2016gcoo6471.

Cyprych, Daria, Sandra Piazolo, Christopher J. L. Wilson, Vladimir Luzin, and David J. Prior. 2016. "Rheology, Microstructure and Crystallographic Preferred Orientation of Matrix Containing a Dispersed Second Phase: Insight from Experimentally Deformed Ice." Earth and Planetary Science Letters 449: 27281.

Dempsey, J. P., D. M. Cole, and S. Wang. 2018. "Tensile Fracture of a Single Crack in First-Year Sea Ice." Philosophical Transactions of the Royal Society A: Mathematical, Physical and Engineering Sciences 376 (2129): 20170346. 
Deville, S., E. Maire, A. Lasalle, A. Bogner, C. Gauthier, J. Leloup, and C. Guizard. 2010. "Influence of Particle Size on Ice Nucleation and Growth During the IceTemplating Process." Journal of the American Ceramic Society 93 (9): 2507-10. doi: 10.1111/j.1551-2916.2010.03840.x.

Deville, Sylvain, Eric Maire, Guillaume Bernard-Granger, Audrey Lasalle, Agnès Bogner, Catherine Gauthier, Jérôme Leloup, and Christian Guizard. 2009. "Metastable and Unstable Cellular Solidification of Colloidal Suspensions." Nature Materials 8 (12): 966.

Durham, William B., Stephen H. Kirby, and Laura A. Stern. 1992. "Effects of Dispersed Particulates on the Rheology of Water Ice at Planetary Conditions." Journal of Geophysical Research: Planets 97 (E12): 20883-97.

Frost, H. J. 1995. Mechanisms of Crack Nucleation in Ice. Los Angeles: University of California.

Frost, H. J., and T. R. Smith. 1992. "Crack Nucleation in Columnar Ice." Proceedings of the 11th IAHR Ice Symposium held at Banff (June).

Gold, L. W. 1966. "Elastic and Strength Properties of Freshwater Ice." NRC Canada 283: $13^{-23 .}$

Gold, Lorne W. 1972. "The Process of Failure of Columnar-Grained Ice." Philosophical Magazine 26 (2): 311-28.

Gold, Lorne W. 2004. "Building Ships from Ice: Habbakuk and After." Interdisciplinary Science Reviews 29 (4): 373-84.

Gow, A. J., S. F. Ackley, W. F. Weeks, and J. W. Govoni. 1982. "Physical and Structural Characteristics of Antarctic Sea Ice." Annals of Glaciology 3: 113-17.

Hammonds, K., and I. Baker. 2017. "Quantifying Damabe in Polycrystlline Ice via X-Ray Computed Micro-tomography." Acta Materialia. doi:

10.1016/j.actamat.2017.01.046.

Hammonds, Kevin, and Ian Baker. 2016. "The Effects of $\mathrm{Ca}++$ on the Strength of Polycrystalline Ice." Journal of Glaciology 62 (235): 954-62.

Haynes, F. Donald, and Jack A Karalius. 1977. "Effect of Temperature on the Strength of Frozen Silt." Hanover, NH: ERDC-CRREL.

Holdsworth, G., and Colin Bull. 1970. "The Flow Law of Cold Ice: Investigations on Meserve Glacier, Antarctica." Institute for Advanced Studies in the Humanities Publications 86: 204-16.

Kingery, W. D. 1963. Ice and Snow: Properties, Processes and Applications. Cambridge, MA: MIT Press.

Lange, Manfred A., and Thomas J. Ahrens. 1983. "The Dynamic Tensile Strength of Ice and Ice-Silicate Mixtures." Journal of Geophysical Research: Solid Earth 88 (B2): 1197-208. 
Li, Jia Hui, Zhen Wei, and Chao Wu. 2015. "Preparation and Properties of Novel Building Materials at Low Temperature." Materials \& Design 67: 464-68. doi: 10.1016/j.matdes.2014.10.040.

Lieb-Lappen, R. M., E. J. Golden, and R. W. Obbard. 2017. "Metrics for Interpreting the Microstructure of Sea Ice Using X-Ray Micro-Computed Tomography." Cold Regions Science and Technology 138: 24-35.

Liu, F., I. Baker, G. Yao, and M. Dudley. 1992. "Dislocations and Grain Boundaries in Polycrystalline Ice: A Preliminary Study by Synchrotron X-Ray Topography." Journal of Materials Science 27 (10): 2719-25.

Petrovic, J. J. 2003. "Review Mechanical Properties of Ice and Snow." Journal of Materials Science 38 (1): 1-6.

Picu, R. C., and V. Gupta. 1995. "Observations of Crack Nucleation in Columnar Ice Due to Grain Boundary Sliding." Acta Metallurgica et Materialia 43 (10): 3791-97.

Ranade, Ravi, Victor C. Li, Michael D. Stults, Todd S. Rushing, Jason Roth, and William F. Heard. 2013. "Micromechanics of High-Strength, High-Ductility Concrete." ACI Materials Journal 110 (4): 375.

Renshaw, Carl E., Narayana Golding, and Erland M. Schulson. 2014. "Maps for Brittle and Brittle-like Failure in Ice." Cold Regions Science and Technology 97: 1-6.

Schleef, Stefan, Henning Löwe, and Martin Schneebeli. 2014. "Hot-Pressure Sintering of Low-Density Snow Analyzed by X-Ray Microtomography and In Situ Microcompression." Acta Materialia 71: 185-94.

Schollick, Julia M. H., Robert W. Style, Arran Curran, John S. Wettlaufer, Eric R. Dufresne, Patrick B. Warren, Krassimir P. Velikov, Roel P. A. Dullens, and Dirk G. A. L. Aarts. 2016. "Segregated Ice Growth in a Suspension of Colloidal Particles." The Journal of Physical Chemistry B 120 (16): 3941-49.

Schulson, E. M. 1999. "The Structure and Mechanical Behavior of Ice." JOM 50 (2): 2127.

Schulson, E. M. 1990. "The Brittle Compressive Fracture of Ice." Acta Metallurgica et Materialia 38 (10): 1963-76.

Schwarz, J., R. Frederking, V. Gavrillo, I. G. Petrov, K.-I. Hirayama, M. Mellor, P. Tryde, and K. D. Vaudrey. 1981. "Standardized Testing Methods for Measuring Mechanical Properties of Ice." Cold Regions Science and Technology 4 (3): 24553 .

Song, M., D. M. Cole, and I. Baker. 2005. "Creep of Granular Ice with and without Dispersed Particles." Journal of Glaciology 51 (173): 210-18. doi: 10.3189/172756505781829377.

Song, Min, Ian Baker, and David M. Cole. 2005. "The Effect of Particles on Dynamic Recrystallization and Fabric Development of Granular Ice During Creep." Journal of Glaciology 51 (174): 377-82. doi: 10.3189/172756505781829287. 
Song, Min, David M. Cole, and Ian Baker. 2006. "An Investigation of the Effects of Particles on Creep of Polycrystalline Ice." Scripta Materialia 55 (1): 91-94. doi: 10.1016/j.scriptamat.2006.03.029.

St. Lawrence, William F., and David M Cole. 1982. "Acoustic Emissions from Polycrystalline Ice." Cold Regions Science and Technology 5 (3): 183-99.

Style, Robert W., Stephen S. L. Peppin, Alan C. F. Cocks, and John S. Wettlaufer. 2011. "Ice-Lens Formation and Geometrical Supercooling in Soils and Other Colloidal Materials." Physical Review E 84 (4): 041402.

Sunder, S. Shyam, and Mao S. Wu. 1990. "Crack Nucleation Due to Elastic Anisotropy in Polycrystalline Ice." Cold Regions Science and Technology 18 (1): 29-47.

Vasiliev, N. K. 1993. "On Development of Fibre-Ice-Composites." Cold Regions Science and Technology 21 (2): 195-99. doi: http://dx.doi.org/10.1016/0165-232X(93)90007$\underline{\mathrm{U}}$.

Vasiliev, N. K., A. D. C. Pronk, I. N. Shatalina, F. H. M. E. Janssen, and R. W. G. Houben. 2015. "A Review on the Development of Reinforced Ice for Use as a Building Material in Cold Regions." Cold Regions Science and Technology 115: 56-63. doi: 10.1016/j.coldregions.2015.03.006.

Wang, Xuan, and Ian Baker. 2013. "Observation of the Microstructural Evolution of Snow under Uniaxial Compression Using X-Ray Computed Microtomography." Journal of Geophysical Research: Atmospheres 118 (22): 12371-82.

Weiss, J., E. M. Schulson, and H. J. Frost. 1996. "The Nucleation of Microcracks in Ice Cubes Compressed Equally on All Boundaries." Philosophical Magazine A 73 (5): 1385-400.

Worster, M. G., and J. S. Wettlaufer. 1997. "Natural Convection, Solute Trapping, and Channel Formation during Solidification of Saltwater." The Journal of Physical Chemistry B 101 (32): 6132-36.

Yasui, Minami, and Masahiko Arakawa. 2008. "Experimental Study on the Rate Dependent Strength of Ice-Silica Mixture with Silica Volume Fractions up to 0.63." Geophysical Research Letters 35 (12): 12206. doi: 10.1029/2008glo33787. 


\section{REPORT DOCUMENTATION PAGE}

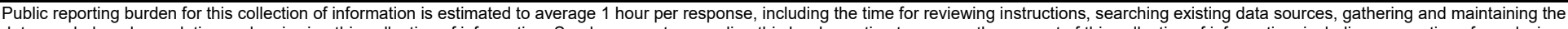

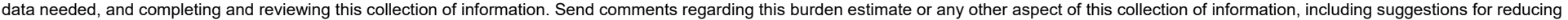

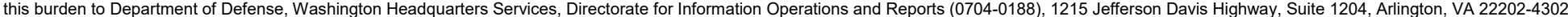

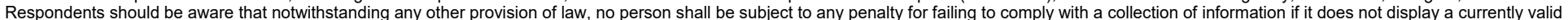
OMB control number. PLEASE DO NOT RETURN YOUR FORM TO THE ABOVE ADDRESS.

\section{REPORT DATE (DD-MM-YYYY) $02 / 2022$ \\ 2. REPORT TYPE \\ Final}

\section{TITLE AND SUBTITLE}

Observation of Crack Arrest in Ice by High Aspect Ratio Particles during Uniaxial Compression
3. DATES COVERED (From - To) FY16-FY17

5a. CONTRACT NUMBER

\section{5b. GRANT NUMBER}

\section{5c. PROGRAM ELEMENT}

622784

\section{AUTHOR(S)}

Emily Asenath-Smith, Ross Lieblappen, Susan Taylor, Reed R. Winter, Terry D. Melendy Jr., Robert D. Moser, Robert B. Haehnel

\section{PERFORMING ORGANIZATION NAME(S) AND ADDRESS(ES)}

US Army Engineer Research and Development Center (ERDC)

Cold Regions Research and Engineering Laboratory (CRREL)

72 Lyme Road

Hanover, NH 03755-1290

\section{5d. PROJECT NUMBER}

458161

5e. TASK NUMBER

0053

5f. WORK UNIT NUMBER

8. PERFORMING ORGANIZATION REPORT NUMBER

ERDC-TR-22-3

\section{SPONSORING / MONITORING AGENCY NAME(S) AND ADDRESS(ES)}

10. SPONSOR/MONITOR'S ACRONYM(S)

11. SPONSOR/MONITOR'S REPORT NUMBER(S)

\section{DISTRIBUTION / AVAILABILITY STATEMENT}

Approved for public release; distribution is unlimited.

\section{SUPPLEMENTARY NOTES}

\section{ABSTRACT}

In nature, ice frequently contains dissolved solutes or entrapped particles, which modify the microstructure and mechanical properties of ice. Seeking to understand the effect of particle shape and geometry on the mechanical properties of ice, we performed experiments on ice containing $15 \mathrm{wt} \%$ silica spheres or rods. Unique to this work was the use of 3-D microstructural imaging in a $-10^{\circ} \mathrm{C}$ cold room during compressive loading of the sample. The silica particles were present in the ice microstructure as randomly dispersed aggregates within grains and at grain boundaries. While cracks originated in particle-free regions in both sphere- and rod-containing samples, the propagation of cracks was quite different in each type of sample. Cracks propagated uninhibited through aggregates of spherical particles but were observed to arrest at and propagate around aggregates of rods. These results imply that spherical particles do not inhibit grain boundary sliding or increase viscous drag. On the other hand, silica rods were found to span grains, thereby pinning together the microstructure of ice during loading. These results provide insights into mechanisms that can be leveraged to strengthen ice.

\section{SUBJECT TERMS}

Ice mechanics, Fracture mechanics, Ice--Cracking, Ice--Microstructure, Ice--Mechanical properties

\section{SECURITY CLASSIFICATION OF:}

\section{a. REPORT}

Unclassified

\section{b. ABSTRACT}

Unclassified

\section{c. THIS PAGE}

Unclassified

\section{LIMITATION} OF ABSTRACT

None
18. NUMBER OF PAGES

31 19a. NAME OF RESPONSIBLE PERSON

19b. TELEPHONE NUMBER (include area code) 